\title{
REMOVAL OF DIVALENT IRON AND MANGANESE IONS AND HYDROGEN SULFIDE FROM GROUNDWATER
}

\author{
Tudor Lupascu*, Mihail Ciobanu, Victor Botan \\ Institute of Chemistry of Academy of Sciences of Moldova, 3, Academiei str., Chisinau MD-2028, Republic of Moldova \\ "e-mail: lupascut@gmail.com; phone: (+373 22) 7254 90; fax: (+373 22) 739954
}

\begin{abstract}
Processes of removal of divalent ions of iron and manganese and hydrogen sulfide from groundwater at various $\mathrm{pH}$ values and temperature were studied. Obtained results have been used in order to elaborate a process of groundwater purification from the mentioned pollutants. The use of elaborated process for natural water leads to the decrease of the content of iron, manganese and hydrogen sulfide below the maximum allowable concentrations.
\end{abstract}

Keywords: divalent iron, divalent manganese, hydrogen sulfide, oxidation, coagulation.

\section{Introduction}

According to the Ministry of Health, the groundwaters of Moldova are of low quality. Around $50 \%$ of groundwater from Moldova is polluted with ions of fluorine, manganese, iron, strontium, ammonium, sulfides etc. Divalent ions of iron and manganese remain common in deep water beyond the permissible concentration. As a result of the oxidation of these ions with airborne oxygen, the water becomes colorized and the problems arise with its use in laundry and deposits within water supply networks. Iron and manganese may be present in one of the basic forms: (1) dissolved - the divalent ions of $\left(\mathrm{Fe}^{2+}\right)$ and $\left(\mathrm{Mn}^{2+}\right)$ and (2) suspended particles of small size corresponding to trivalent iron hydroxides $\left(\mathrm{Fe}(\mathrm{OH})_{3}\right)$ and tetravalent manganese hydroxides $\left(\mathrm{Mn}(\mathrm{OH})_{4}\right)$. The nature of these forms depends on the value of $\mathrm{pH}$, Eh (redox potential) and the water temperature. Hydrogen sulfide is found in groundwater in its dissolved form $\left(\mathrm{H}_{2} \mathrm{~S}\right)$ or as metal sulfides $\left(\mathrm{Me}_{\mathrm{n}} \mathrm{S}_{\mathrm{m}}\right)$. The knowledge of the species and the oxidation state of iron, manganese and hydrogen sulfide contribute to the elaboration of the water treatment process.

Scientific literature describes the procedure of removal of divalent ions of iron, manganese and hydrogen sulfide from various types of water [1-3]. In [1] for the removal of iron and manganese ions from water the MFO-47 filter was used, which contains a material of natural origin $(\mathrm{CaC})_{\mathrm{n}}$. On the surface of this material, a catalytically active layer was applied, which consisting of a mixture of oxides $\mathrm{MnO}, \mathrm{Mn}_{2} \mathrm{O}_{3}$ and $\mathrm{MnO}_{2}$. This filter material removes only iron and manganese ions from water. In [2] there is mentioned that the treatment with reagents of this natural disperse material leads to material changes. On the surface of the natural material, a mixture of manganese hydroxide and oxides $\left(\mathrm{Mn}(\mathrm{OH})_{2}, \mathrm{Mn}_{2} \mathrm{O}_{3}, \mathrm{MnO}_{2}\right)$ is formed. The presence of manganese hydroxide on catalyst surface contributes to the efficient oxidation of hydrogen sulfide, forming a weak dibasic acid. In [4] there is mentioned that for the removal of iron and manganese ions and hydrogen sulfide from groundwater, a mineral adsorbent surface was used, which has incorporated a catalytically active layer, containing the same mixture of $\mathrm{Mn}(\mathrm{OH})_{2}, \mathrm{Mn}_{2} \mathrm{O}_{3}$ and $\mathrm{MnO}_{2}$, in a mass ratio (1$0.5):(3-2):(6-5)$, respectively. The filter material is obtained using two solutions that contain salts of manganese, the first salt containing bivalent manganese sulfate and sodium sulfate and the second - sodium permanganate solution.

The aim of this research was to study the processes and mechanisms of removal of divalent iron and manganese ions and hydrogen sulfide from groundwater. Manganese is present as $\mathrm{Mn}^{2+}$ at the value of $\mathrm{pH}$ between 0 and 8.4 and as $\mathrm{Mn}(\mathrm{OH})_{4}$ when $8.4 \leq \mathrm{pH} \leq 14$, while $\mathrm{Fe}^{3+}$ at $\mathrm{pH}=9.5$ is present in the form of $\mathrm{Fe}(\mathrm{OH})_{3}$ [5]. Based on these data, the possibility to remove the iron and manganese divalent ions as a result of $\mathrm{pH}$ change was studied.

\section{Experimental}

The chemical composition of groundwater from village Sculeni (Ungheni district) and the maximum allowable concentrations (MAC) of detected chemical components, according to the current regulations, are presented in Table 1.

As shown in Table 1, the content of iron exceeds the maximum allowable concentration by 4.3 times, manganese - by 9 times and hydrogen sulfide slightly exceeds the MAC.

The treatment processes (adsorption/catalytic oxidation and precipitation) of water polluted by the bivalent ions of manganese and iron, as well as hydrogen sulfide were carried out using the installation presented in Figure 1. The model solution, which contained $\mathrm{Fe}-1.24 \mathrm{mg} / \mathrm{dm}^{3}, \mathrm{Mn}-0.47 \mathrm{mg} / \mathrm{dm}^{3}$ and $\mathrm{H}_{2} \mathrm{~S}-0.12 \mathrm{mg} / \mathrm{dm}^{3}$, appropriate to the real water from the village Sculeni, was used in the experimental tests. In order to oxidize only hydrogen sulfide to sulfate, the $1.8 \mathrm{~cm}^{3}$ of $35 \% \mathrm{H}_{2} \mathrm{O}_{2}$ was added to the volume of $10 \mathrm{dm}^{3}$, by mixing for 10 minutes. The value of $\mathrm{pH}$ was then adjusted to 10.25 . The removal process of iron and manganese ions was carried out by stirring for 20 minutes at a temperature of $15^{\circ} \mathrm{C}$. During this time the precipitation floccules appear which representing three valence iron hydroxide and four valence manganese hydroxide. The water from the reactor was passed through a sand filter, fraction 0.8 to 1.3 $\mathrm{mm}$ by means of a pump. The filtration speed was $7 \mathrm{~m} / \mathrm{h}$. After filtration, the water was subjected to laboratory analysis in order to establish the concentrations of iron, manganese and sulfur. 
Chemical composition of groundwater from village Sculeni and maximum allowable concentration (MAC) of mentioned components.

\begin{tabular}{lcc}
\hline \multicolumn{1}{c}{ Parameter name and unit } & Determined & MAC \\
\hline Total hardness, $\mathrm{mol} / \mathrm{dm}^{3}$ & 6.16 & 5.0 \\
Dry residue $\left(110^{\circ} \mathrm{C}\right), \mathrm{mg}^{3} \mathrm{dm}^{3}$ & 498.4 & 1500 \\
Nitrites $\left(\mathrm{NO}_{2}^{-}\right), \mathrm{mg} / \mathrm{dm}^{3}$ & 0.0075 & 0.5 \\
Nitrates $\left(\mathrm{NO}_{3}^{-}\right), \mathrm{mg} / \mathrm{dm}^{3}$ & $<0.5$ & 50 \\
Iron $(\mathrm{Fe})$ total, $\mathrm{mg} / \mathrm{dm}^{3}$ & 1.29 & 0.3 \\
Ammonia $\left(\mathrm{NH}_{4}^{+}\right), \mathrm{mg} / \mathrm{dm}^{3}$ & 0.37 & 0.5 \\
Sodium $\left(\mathrm{Na}^{+}\right), \mathrm{mg} / \mathrm{dm}^{3}$ & 45.7 & 200 \\
Fluorine $(\mathrm{F}), \mathrm{mg} / \mathrm{dm}^{3}$ & $<0.2$ & 1.5 \\
Copper $(\mathrm{Cu}), \mathrm{mg} / \mathrm{dm}^{3}$ & $<0.1$ & 1.0 \\
Cadmium $(\mathrm{Cd}), \mathrm{mg} / \mathrm{dm}^{3}$ & $<0.001$ & 0.003 \\
Chromium $(\mathrm{C}), \mathrm{mg} / \mathrm{dm}^{3}$ & $<0.01$ & 0.05 \\
Manganese $(\mathrm{Mn}), \mathrm{mg} / \mathrm{dm}^{3}$ & 0.45 & 0.05 \\
$\mathrm{H}_{2} \mathrm{~S}, \mathrm{mg} / \mathrm{dm}^{3}$ & 0.12 & 0.1 \\
\hline
\end{tabular}

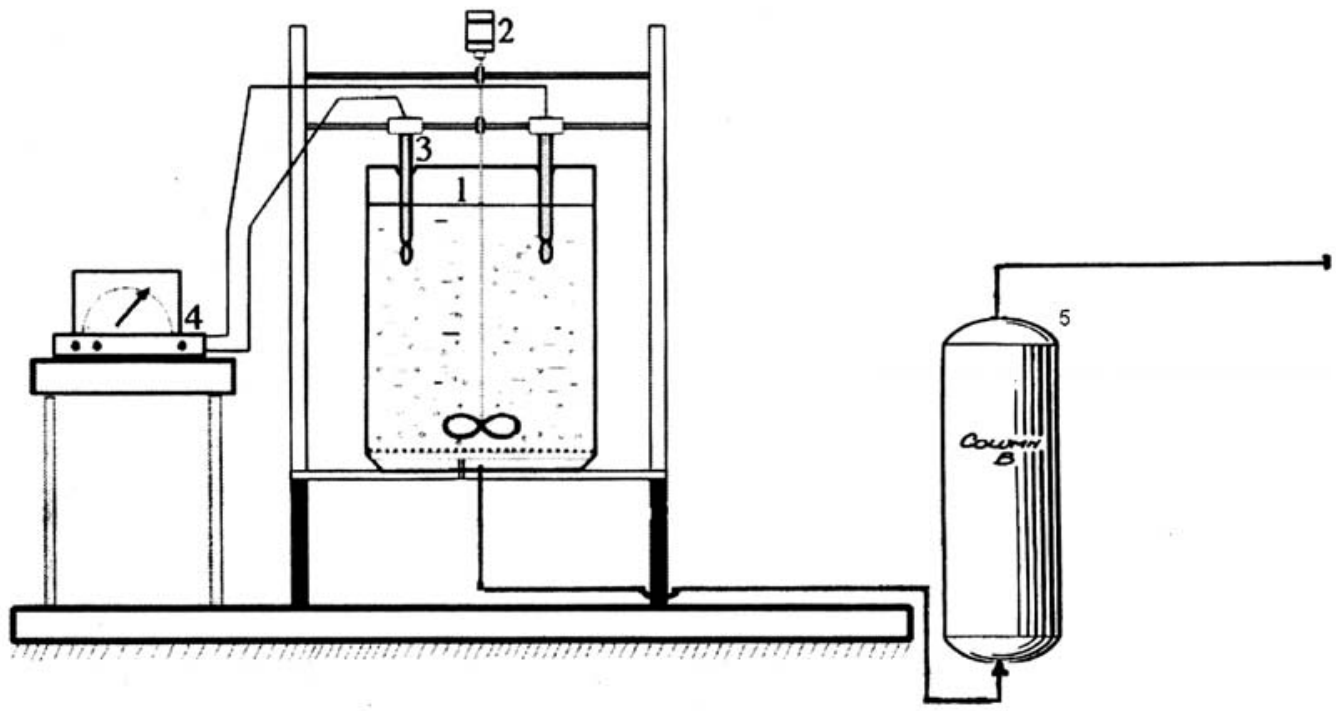

Figure 1. Scheme of the installation for the testing of the process of removal of $\mathrm{Fe}, \mathrm{Mn}, \mathrm{H}_{2} \mathrm{~S}$ from groundwater.

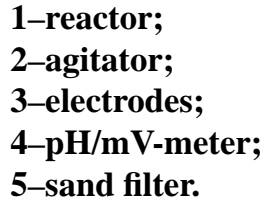

\section{Results and discussion}

The results of the analyzes of purified water is as follows: (i) the concentration of sulfate ions initially was $60.1 \mathrm{mg} / \mathrm{dm}^{3}$ and after the treatment increased to $63.3 \mathrm{mg} / \mathrm{dm}^{3}$ due to the oxidation of $1.2 \mathrm{mg} / \mathrm{dm}^{3}$ of hydrogen sulfide; (ii) the concentration of hydrogen sulfide after treatment became 0 ; the initial $\mathrm{pH}$ of the water was 10.25 and after filtration became 9.9; (iii) the concentration of iron and manganese after treatment was $0.12 \mathrm{mg} / \mathrm{dm}^{3}$ and $<0.05 \mathrm{mg} / \mathrm{dm}^{3}$, respectively. Test results allow us to conclude that the developed method allows treating the groundwater contaminated with bivalent ions of iron, manganese and hydrogen sulfide. These processes can be described by the following chemical reactions:

$$
\begin{gathered}
\mathrm{H}_{2} \mathrm{~S}+4 \mathrm{H}_{2} \mathrm{O}_{2} \rightarrow \mathrm{H}_{2} \mathrm{SO}_{4}+4 \mathrm{H}_{2} \mathrm{O} \\
4 \mathrm{FeCl}_{2}+8 \mathrm{NaOH}+\mathrm{O}_{2}+2 \mathrm{H}_{2} \mathrm{O} \rightarrow 4 \mathrm{Fe}(\mathrm{OH})_{3}+8 \mathrm{NaCl}
\end{gathered}
$$


$2 \mathrm{M}_{\mathrm{n}} \mathrm{Cl}_{2}+4 \mathrm{NaOH}+\mathrm{O}_{2}+2 \mathrm{H}_{2} \mathrm{O} \rightarrow 2 \mathrm{M}_{\mathrm{n}}(\mathrm{OH})_{4}+4 \mathrm{NaCl}$

Groundwater is used daily throughout the year at various temperatures. In these conditions, it is the necessary to perform the scientific research, regarding the influence of temperature and the value of $\mathrm{pH}$ on the process of removal of iron and manganese ions and hydrogen sulfide, as these factors are changing in dependence on the season.

The data on the removal of iron, manganese ions and hydrogen sulfide from groundwater at various values of $\mathrm{pH}$ and temperature are presented in the Table 2.

Removal of iron, manganese and hydrogen sulfide from groundwater

Table 2 at various values of $\mathbf{p H}$ and temperature.

\begin{tabular}{ccccccccc}
\hline \multirow{2}{*}{ Temperature, ${ }^{\circ} \mathrm{C}$} & $\begin{array}{c}\text { Volume of } \mathrm{H}_{2} \mathrm{O}_{2}, \\
\mathrm{~cm}^{3}\end{array}$ & \multicolumn{2}{c}{ Value of $\mathrm{pH}$} & \multicolumn{3}{c}{$\begin{array}{c}\text { Final amount, } \\
\mathrm{mg} / \mathrm{dm}^{3}\end{array}$} & \multicolumn{3}{c}{$\begin{array}{c}\text { Amount of SO }{ }_{4}^{2-}, \\
\mathrm{mg}^{2} \mathrm{dm}^{3}\end{array}$} \\
\cline { 2 - 9 } & 1.80 & initial & final & $\mathrm{H}_{2} \mathrm{~S}$ & $\mathrm{Fe}^{2+}$ & $\mathrm{Mn}^{2+}$ & initial & final \\
\hline $10^{\circ} \mathrm{C}$ & 1.80 & 9.45 & 8.85 & 0.0 & 0.086 & 0.000 & 65.56 & 70.80 \\
$15^{\circ} \mathrm{C}$ & 1.80 & 9.80 & 9.25 & 0.0 & 0.086 & 0.000 & 65.60 & 70.40 \\
$15^{\circ} \mathrm{C}$ & 4.00 & 10.25 & 10.15 & 0.0 & 0.100 & 0.020 & 65.50 & 71.60 \\
$15^{\circ} \mathrm{C}$ & 1.80 & 9.50 & 9.45 & 0.0 & 0.070 & 0.078 & 67.20 & 72.50 \\
$22.5^{\circ} \mathrm{C}$ & 1.80 & 9.40 & 8.70 & 0.0 & 0.084 & 0.105 & 65.50 & 69.60 \\
$32^{\circ} \mathrm{C}$ & & & & & & 0.052 & 0.084 & 65.56 \\
\hline
\end{tabular}

The data presented in this table show that the optimal conditions for removal of such pollutants from water are: temperature of $10-15{ }^{\circ} \mathrm{C}$, the hydrogen peroxide concentration $-1.8 \mathrm{mg} / \mathrm{dm}^{3}$, and its initial $\mathrm{pH}$ is adjusted to 9.45 . The value of $\mathrm{pH}$ after treatment is equal to 8.85 , which is below the drinking water standard, according to current regulations in the Republic of Moldova. The technological flowsheet for the treatment of groundwater in the village Sculeni is shown in Figure 2.

The total content of sulfides in many places of Moldova is more than $10 \mathrm{mg} / \mathrm{dm}^{3}$. Taking this fact into account, the identification of the treatment solutions for groundwater with a high content of sulfides is of interest. During the removal of hydrogen sulfide, into the $10 \mathrm{dm}^{3}$ of water, which contained the $10 \mathrm{mg} / \mathrm{dm}^{3} \mathrm{H}_{2} \mathrm{~S}$ and $70.1 \mathrm{mg} / \mathrm{dm}^{3} \mathrm{SO}_{4}^{2-}$, the $4 \mathrm{~cm}^{3}$ of $35 \% \mathrm{H}_{2} \mathrm{O}_{2}$ were added and stirred. Samples were removed every $5 \mathrm{~min}$ for the determination the sulfides concentration. The kinetics of sulfides removal from the studied water is illustrated in Figure 3.

The presented data show an increase of sulfates concentration from $70.1 \mathrm{mg} / \mathrm{dm}^{3}$ to $\sim 100 \mathrm{mg} / \mathrm{dm}^{3}$ in a short time ( $\sim 8 \mathrm{~min})$, which proves that the oxidation of hydrogen sulfide occurred and the all hydrogen sulfide present in water was transformed to sulfates.

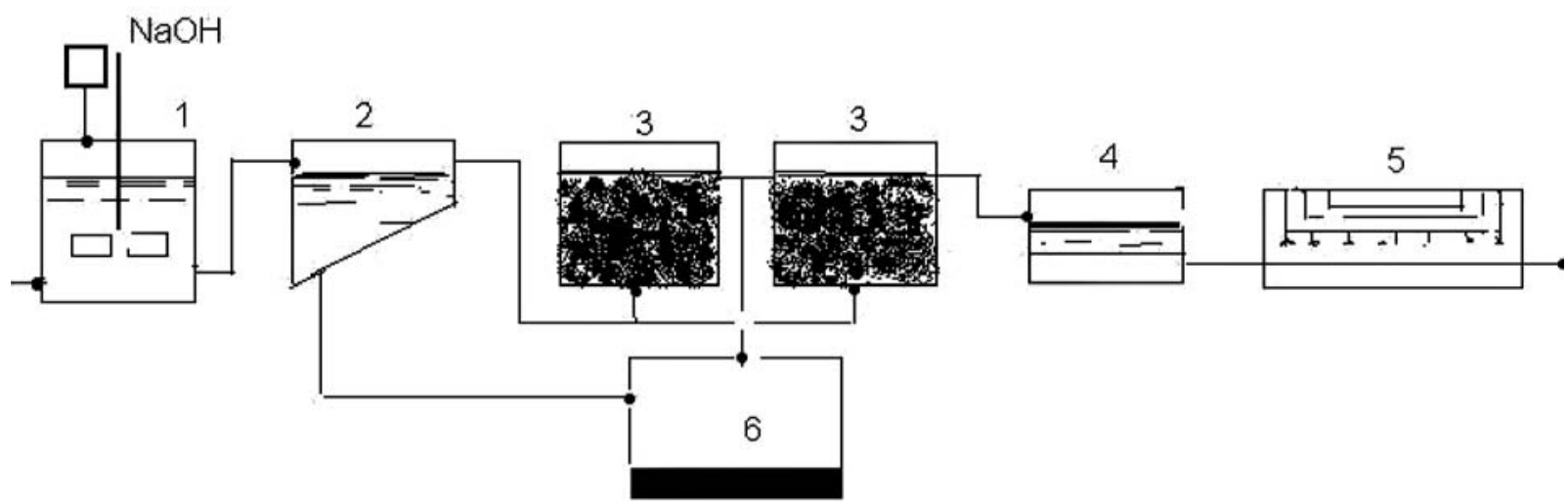

Figure 2. Technological scheme of the removal of iron and manganese divalent ions and of hydrogen sulfide from the groundwater of village Sculeni, district Ungheni.

1-reactor-agitator;

2-decanter;

3-sand filter; 4-water reservoir;

5-UV disinfection unit;

6- wastewater reservoir. 


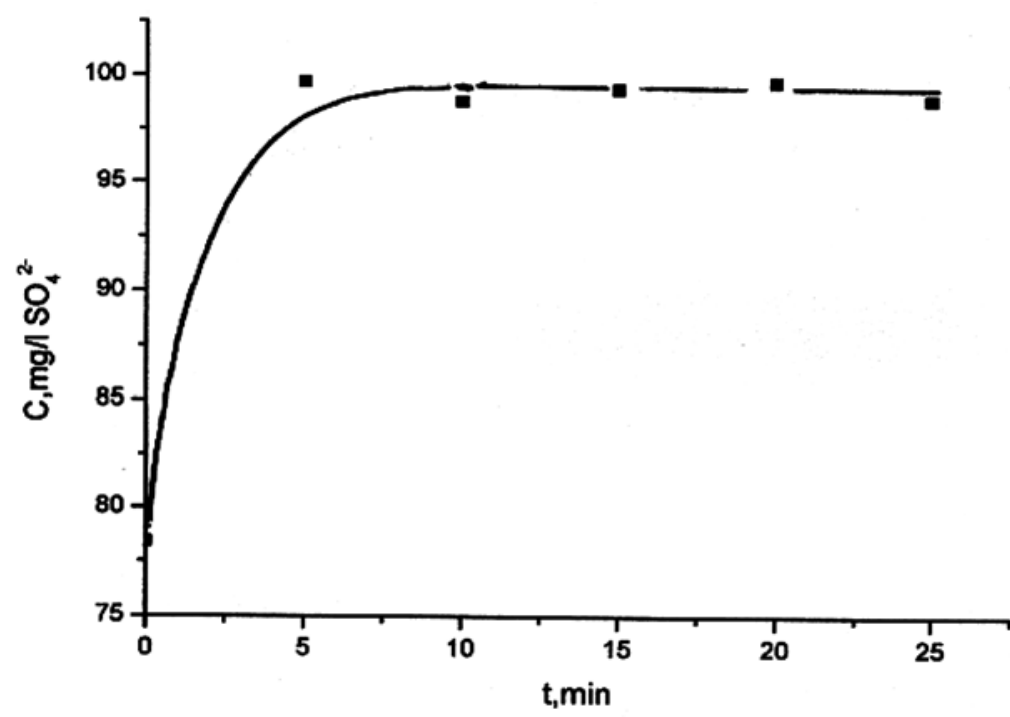

Figure 3. Kinetics of sulfides oxidation from modeled water (10 mg/dm ${ }^{3}$ sulfides, $4 \mathrm{~cm}^{3} \mathrm{H}_{2} \mathrm{O}_{2}$ in $10 \mathrm{dm}^{3}$ water).

\section{Conclusions}

Processes and mechanisms of divalent ions of iron and manganese and hydrogen sulfide removal from groundwater have been studied.

The maximum efficiency of the removal of divalent ions of iron and manganese and hydrogen sulfide from the studied water was established at a temperature of $10-15^{\circ} \mathrm{C}$ and $\mathrm{pH}$ adjusted to 9.45 .

After filtration of purified water, the value of $\mathrm{pH}$ is 8.85 , this value being at the upper limit of $\mathrm{pH}$ of drinking water standard.

Hydrogen sulfide and sulfides are oxidized to sulfates using as oxidant concentrated hydrogen peroxide.

\section{References}

1. Goncikov, V.C.; Gubaidullina, V.C.; Kaminskaia, P.A.; Apcarian, A.C. Filtering material for water purification from iron, manganesse and hydrogen sulfide. Buletine of Poliutechnik University from Tomsk, 2012, 320(3), pp. 37-40 (in Russian).

2. Gubaidullina, T.A.; Melnikov, A.G. Proceedings of the IX International Scientific-Practical Conference. Kemerovo, Russian Federation, May 16-17, 2006. pp. 204-206 (in Russian).

3. Lupascu, T.; Ciobanu, M.; Botan, V.; Gromovoy, T.; Cibotaru, S.; Petuhov, O.; Mitina T. Study of hydrogen sulfide removal from grundwater. Chemistry Journal of Moldova, 2013, 8(1), pp. 37-42.

4. Gubaidullina, T.A.; Kaminskaia, P.A.; Apcarian, A.C. Filtering material for purification water from iron, manganesse and hydrogen sulfide and the method for its preparation. Russian Federation Patent, 2010 , No. 2447922 (in Russian).

5. Fistic, I.F.; Vataman, I.I. Thermodynamics of the hydrolysis of metal ions. Kisinev, Stiinta, 1988. 294 p. (in Russian). 